\title{
The Antitumor Effects of Metformin on Gastric Cancer In Vitro and on Peritoneal Metastasis
}

\author{
NOBUFUMI SEKINO, MASAYUKI KANO, YASUNORI MATSUMOTO, HARUHITO SAKATA, \\ KENTARO MURAKAMI, TAKESHI TOYOZUMI, RYOTA OTSUKA, MASAYA YOKOYAMA, TADASHI SHIRAISHI, \\ KOICHIRO OKADA, TOSHIKI KAMATA, TAKAHIRO RYUZAKI and HISAHIRO MATSUBARA
}

Department of Frontier Surgery, Graduate School of Medicine, Chiba University, Chiba, Japan

\begin{abstract}
Background/Aim: Gastric cancer (GC) with peritoneal metastasis remains difficult to treat. The antidiabetic drug metformin exerts various antitumor effects via the 5'-adenosine monophosphate-activated protein kinase $($ AMPK) pathway and nuclear factor-kappa $B(N F-k B)$. Therefore, we evaluated the antitumor effects of metformin for $G C$ in vitro and on peritoneal metastasis. Materials and Methods: The human GC cell lines MKN1, MKN45, KATOIII and SNU-1 were used. The antiproliferative effect was evaluated in vitro with $0.5 \mathrm{mM}$ or $25 \mathrm{mM}$ glucose and in vivo using tumor xenograft peritoneal models of metastasis. The protein expression of $A M P K$, liver kinase B1 (LKB1) and $N F-k B$ in tumors was examined by western blotting. Results: Metformin inhibited cell proliferation in all GC lines and sensitivity was increased under low-glucose conditions in vitro. Metformin also suppressed peritoneal metastasis. In tumors, metformin reduced the numbers of proliferating cells and $N F-k B$ expression, but a similar trend was not noted for AMPK. Conclusion: Metformin may be a useful drug for the treatment of GC with peritoneal metastasis.
\end{abstract}

Gastric cancer (GC), is an intractable digestive organ cancer that has a high incidence in East Asia. Peritoneal metastasis is a particularly serious, life-threatening mode of metastasis and remains difficult to treat despite chemotherapy (1).

Metformin is a widely used for the treatment of diabetes mellitus, and its antitumor effects have been reported in recent years (2). Metformin exerts antitumor effects against many kinds of cancer, including hepatocellular carcinoma (3), cholangiocarcinoma (4), and colorectal (5), pancreatic

Correspondence to: Masayuki Kano, Department of Frontier Surgery, Graduate School of Medicine, Chiba University, 1-8-1 Inohana, Chuo-ku, Chiba-shi, Chiba 260-8670, Japan. Tel: +81 432262109, Fax: +81 432262113, e-mail: mkano@ chiba-u.jp

Key Words: Metformin, gastric cancer, peritoneal metastasis, glucose, NF-kB.
(6), breast (7) and ovarian (8) cancer. Furthermore, a tumorpreventive effect of metformin has also been reported, as administering metformin prior to subcutaneous injection of esophageal squamous cell carcinoma reduced the tumor size (9).

A previous report found that metformin targets multiple signaling pathways in cancer. Metformin activates 5'adenosine monophosphate-activated protein kinase (AMPK) signaling via liver kinase B1 (LKB1) (10) and inhibits nuclear factor-kappa B (NF-kB) signaling. In this way, metformin induces apoptosis and cell-cycle arrest and suppresses cell migration and invasion (11). We previously reported on the antitumor effects of metformin in esophageal squamous cell carcinoma due to inhibition of NF-KB (12). Another interesting report found that the glucose concentration in the medium for cell culture affects sensitivity to metformin (13). Furthermore, it has been reported that the concentration of glucose in solid tumor is $\leq 0.5 \mathrm{mM}$ (14). Therefore, when studying metformin, attention should be paid to the glucose concentration under the experimental conditions, but there are few reports researching from this viewpoint.

Thus, many antitumor effects of metformin have been reported in many types of cancer; however, only a few reports of the correlation between metformin and GC have been published. A meta-analysis of cohort studies showed that the risk of GC among patients with type 2 diabetes mellitus may decrease by taking metformin (15), but its effect on peritoneal metastasis is not mentioned. Metformin may inhibit the dissemination of colon cancer because the odds of dissemination were lower in metformin-treated diabetic patients than in untreated patients (16), but no reports have described a direct correlation between metformin and peritoneal metastasis of GC.

Several studies have examined the mechanisms of peritoneal metastasis, and many genes have been identified as being associated with this process (17). Generally, the genes were found mainly to be associated with epithelialmesenchymal transition (EMT), inflammation and cell 
proliferation. Metformin was found to inhibit EMT, which is greatly associated with peritoneal metastasis of GC cells (18), and suppress the migration and invasion of GC cells (19). Inflammation induces tumor promotion and has a strong correlation with EMT. There are many cell signals that induce EMT, and inflammatory signals such as NF-kB also induce EMT (20). NF-kB, the nuclear translocation of which was inhibited by metformin in esophageal squamous cell carcinoma, is also reported to be an important signal in peritoneal metastasis (21). Metformin is also said to target stem cells in GC (22), and constitutive activation of NF-kB is necessary for stem cell maintenance in breast cancer (23), as well as in human induced pluripotent stem cells (24). However, no reports have described the relationship between $\mathrm{NF}-\mathrm{kB}$ and metformin in GC.

Given the above previous findings, we examined the antitumor effect of metformin in GC, with a focus on peritoneal metastasis.

\section{Materials and Methods}

$G C$ cell culture and regents. The human GC cell lines MKN1, MKN45 and KATO-III were purchased from RIKEN Bioresource Cell Bank (Tsukuba, Ibaraki, Japan), and green fluorescent protein labeled MKN45 cells (MKN45-GFP) were established in our laboratory. SNU-1 cells were purchased from the American Type Culture Collection (Manassas, VA, USA). The cells were cultured in Dulbecco's modified Eagle's Medium (DMEM)/Ham's F-12 (Sigma-Aldrich, St. Louis, MO, USA) supplemented with $10 \%$ fetal bovine serum (FBS) in a humidified incubator containing $5 \% \mathrm{CO}_{2}$ at $37^{\circ} \mathrm{C}$. Medium with a low glucose concentration was obtained by mixing with complete DMEM/Ham's F-12 medium and glucosefree DMEM/Ham's F-12 medium (Nacalai Tesque, Kyoto, Japan). Metformin was purchased from Sigma Chemical Co. (St. Louis, MO, USA). Penicillin and streptomycin were obtained from North China Pharmaceutical Group Corp (Shijiazhuang, China). We obtained $0.05 \%$ trypsin-EDTA and FBS from Invitrogen Life Technologies (Carlsbad, CA, USA). A Cell Counting Kit-8 (CCK8) was purchased from Dojindo (Kumamoto, Japan).

$C C K-8$ viability assay. The inhibitory influence of cell proliferation by metformin was assessed by evaluating the cell viability using a CCK- 8 assay. Cells were seeded in 96 -well plates at $5 \times 10^{3}$ cells per well and cultured for $24 \mathrm{~h}$ at $37^{\circ} \mathrm{C}$. Cells were exposed to different concentrations of metformin $(0.01$ to $30 \mathrm{mM})$ for $72 \mathrm{~h}$, and the antiproliferative effects were determined using Cell Counting Kit-8. The absorbance was determined at $450 \mathrm{~nm}$ using a microplate reader.

Tumor xenograft peritoneal metastasis model. Six-week-old Balb/C nude mice (Japan SLC Inc. Hamamatsu, Shizuoka, Japan) were used to establish a MKN45-GFP tumor xenograft model of peritoneal metastasis. Nude mice were reared in a specific-pathogen-free facility. MKN45-GFP cells were harvested and injected $5 \times 10^{6}$ cells into the intraperitoneal space of mice. The mice were randomized into a control group and a treatment group (four mice per group). From the next day, the mice in the treatment group were administered metformin $(5 \mathrm{mg} / \mathrm{mice})$ via intraperitoneal injection, while those in the control group were administered phosphatebuffered saline (PBS) $100 \mu$ five times a week. Treatments were performed for 35 days, and the tumor weights were determined. The body weight of mice was measured periodically.

Ki67 staining. Tumor tissues were embedded in paraffin and then sectioned at $4 \mu \mathrm{m}$ and deparaffinized. Proliferating cells in tumor tissues were detected based on Ki67 immunohistochemistry using Monoclonal Mouse Anti-Human Ki-67 Antigen (Dako, Glostrup, Denmark).

Western blotting. The tumors were lysed with radioimmunoprecipitation assay buffer. The western blot analysis was performed on an XV PANTERA Gel 7.5-15\% (DRC, Tokyo, Japan). The proteins in the gels were transferred electrophoretically onto nitrocellulose membranes. Anti-human LKB1 mouse monoclonal immunoglobulin (Ig) G (Cell Signaling Technology, Danvers, MA, USA), anti-human AMPK $\alpha$ mouse polyclonal IgG (Cell Signaling Technology), anti-human phospho-AMPK $\alpha$ (p-AMPK $\alpha$ ) rabbit monoclonal IgG (Cell Signaling Technology), anti-human NF-kB p65 rabbit polyclonal IgG (Abcam, Cambridge, UK) and antihuman Glyceraldehyde 3-phosphate dehydrogenase (GAPDH) rabbit polyclonal $\mathrm{IgG}$ (Abcam) were used as primary antibodies. The expression of each protein was detected using secondary antibodies conjugated to peroxidase-labeled polymers. Rabbit or mouse IgG antibodies (Invitrogen) were used as secondary antibodies. Can Get Signal (TOYOBO, Osaka, Japan) was used as an immunoreaction enhancer solution. Bands were visualized using the Amersham ECL Prime Western blotting reagent (GE Healthcare Life Sciences, Uppsala, Sweden). Densitometry was performed using ImageJ software (NIH, Bethesda, MD, USA).

Statistical analyses. Data were analyzed by $t$-tests conducted using Excel software (Microsoft, Redmond, WA, USA). A value of $p<0.05$ was considered to indicate significance.

\section{Results}

Proliferation assay in GC cell lines MKN1, MKN45-GFP, KATO-III and SNU-1. The growth-inhibitory effect of metformin on MKN45-GFP, MKN1, KATO-III and SNU-1 cells was examined by a proliferation assay (Figure 1A) treated with a high glucose concentration $(25 \mathrm{mM})$. Metformin inhibited cell proliferation in all GC cell lines in a dosedependent manner. However, there was a marked difference in the sensitivity among these cell lines. In the study under a low-glucose condition (0.5 mM) in MKN45-GFP (Figure 1B), MKN1 (Figure 1C), KATO-III (Figure 1D) and SNU-1 (Figure 1E) cells, the sensitivity of metformin was greatly increased, and the half-maximal (50\%) inhibitory concentration $\left(\mathrm{IC}_{50}\right)$ concentration of metformin differed among MKN1 (high: $4.4 \mathrm{mM}$, low: $1.9 \mathrm{mM}$ ), KATO-III (high: $13.4 \mathrm{mM}$, low: $0.6 \mathrm{mM}$ ) and SNU-1 cells (high: $14.1 \mathrm{mM}$, low: $1.9 \mathrm{mM}$ ), but a similar trend was not noted in MKN45GFP cells (high: $1.4 \mathrm{mM}$, low: $1.4 \mathrm{mM}$ ).

Tumor growth, cell proliferation and apoptosis in vivo. The tumor volume was measured on day 35 after injecting the 


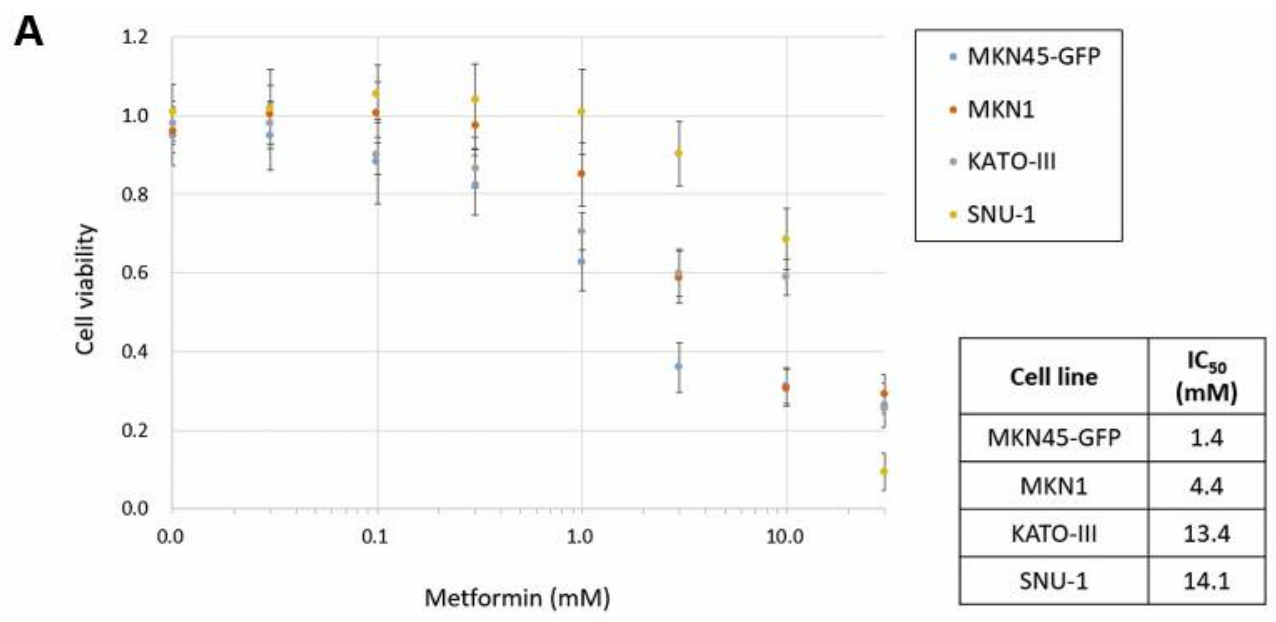

B

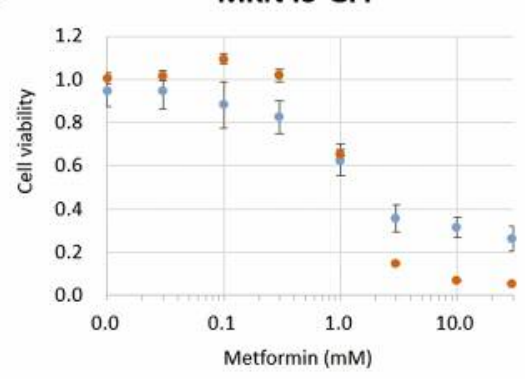

D

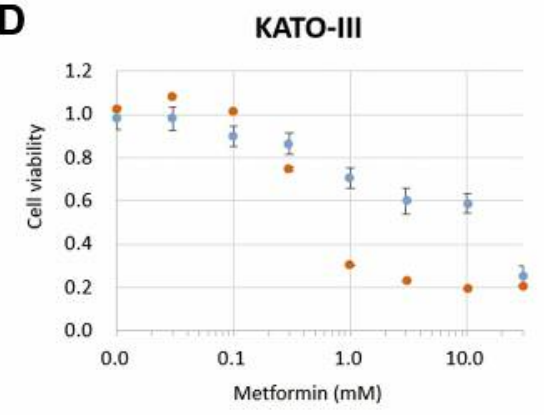

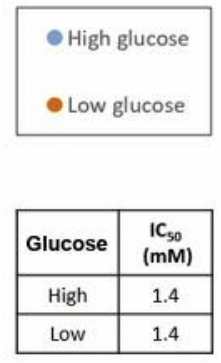
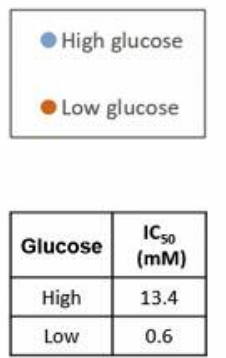

C
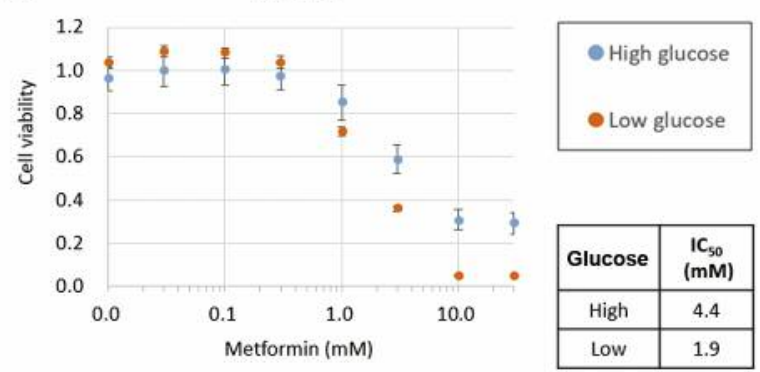

E

SNU-1

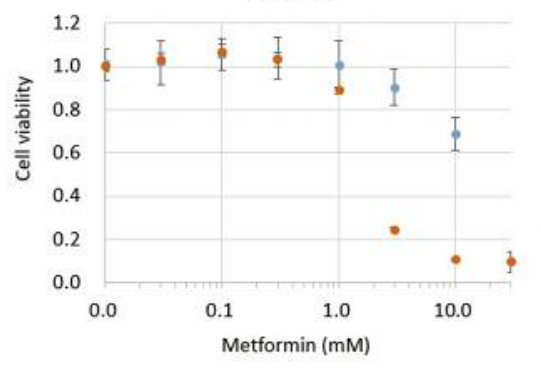

- High glucose

- Low glucose

\begin{tabular}{|c|c|}
\hline Glucose & $\begin{array}{c}\mathbf{I C}_{50} \\
(\mathrm{mM})\end{array}$ \\
\hline High & 14.1 \\
\hline Low & 1.9 \\
\hline
\end{tabular}

Figure 1. Metformin inhibits proliferation of gastric cancer cell lines in vitro. A: Metformin inhibited cell proliferation in a dose-dependent manner in MKN45-GFP, MKN1, KATO-III and SNU-1 cells, but the sensitivities differed among these gastric cancer cell lines. B-E: The results of proliferation assays under high- $(25 \mathrm{mM})$ and low- $(0.5 \mathrm{mM})$ glucose conditions in MKN45-GFP (B), MKN1 (C), KATO-III (D) and SNU-1 (E) cells are shown. Data are means \pm S.D., $n=8$.

MKN45-GFP cells. The total tumor volume was significantly smaller in the metformin-treated group than in the control group (Figure 2A, $p=0.029$ ). There were no significant differences in the body weight between the control group and the metformintreated group (Figure 2B, day 1: $p=0.344$; day 35: $p=0.216$ ).

The histology of the tumors was examined (Figure 3A). Proliferating cells were detected by Ki67 staining. On tumors in the control group and the metformin-treated group, hematoxylin and eosin and Ki67 staining were performed. There were significantly fewer Ki67-positive proliferating cells in the tumors in the metformin-treated group than in the control group (Figure 3B, $p=0.011$ ).

AMPK pathway activity. The effect of metformin on the AMPK pathway was evaluated by a western blotting analysis (Figure 4). The protein expression of the key molecules of 
A

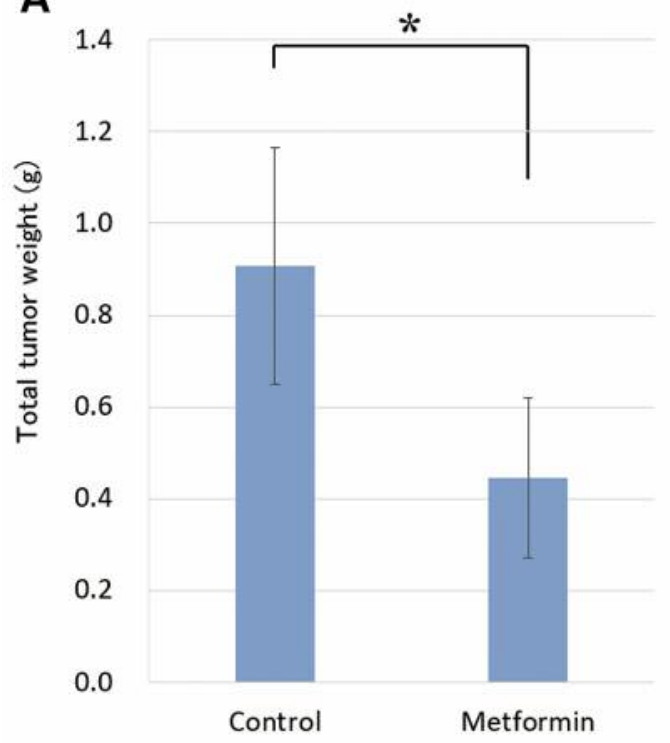

B

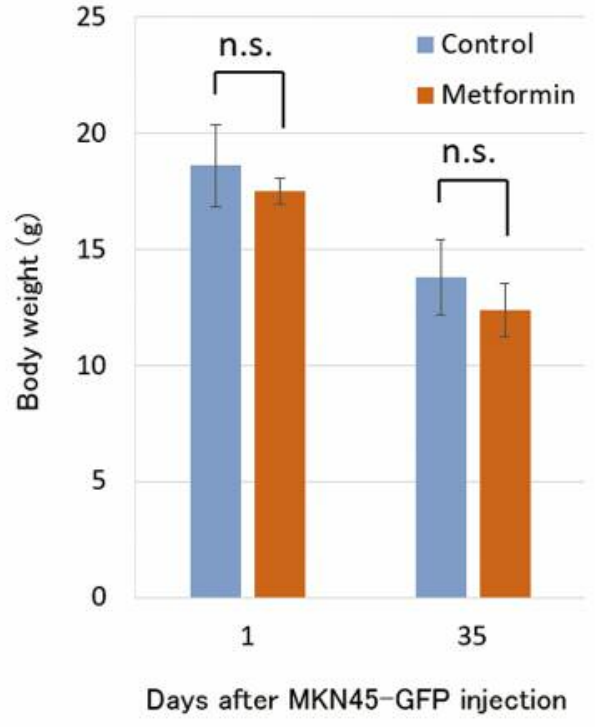

Figure 2. Metformin suppressed peritoneal metastasis of gastric cancer in vivo. A: The total tumor weight is shown. Control group: $n=4$, metformintreated group: $n=4$, *Significantly different at $p=0.029$, bar: S.D. B: The mouse body weight was measured at 1 and 35 days after intraperitoneal injection of MKN45-GFP cells. The body weight did not differ significantly between the control group and the metformin-treated group at the time of measurement ( $p=0.345)$. Data are means \pm S.D. n.s.: Non-significant.

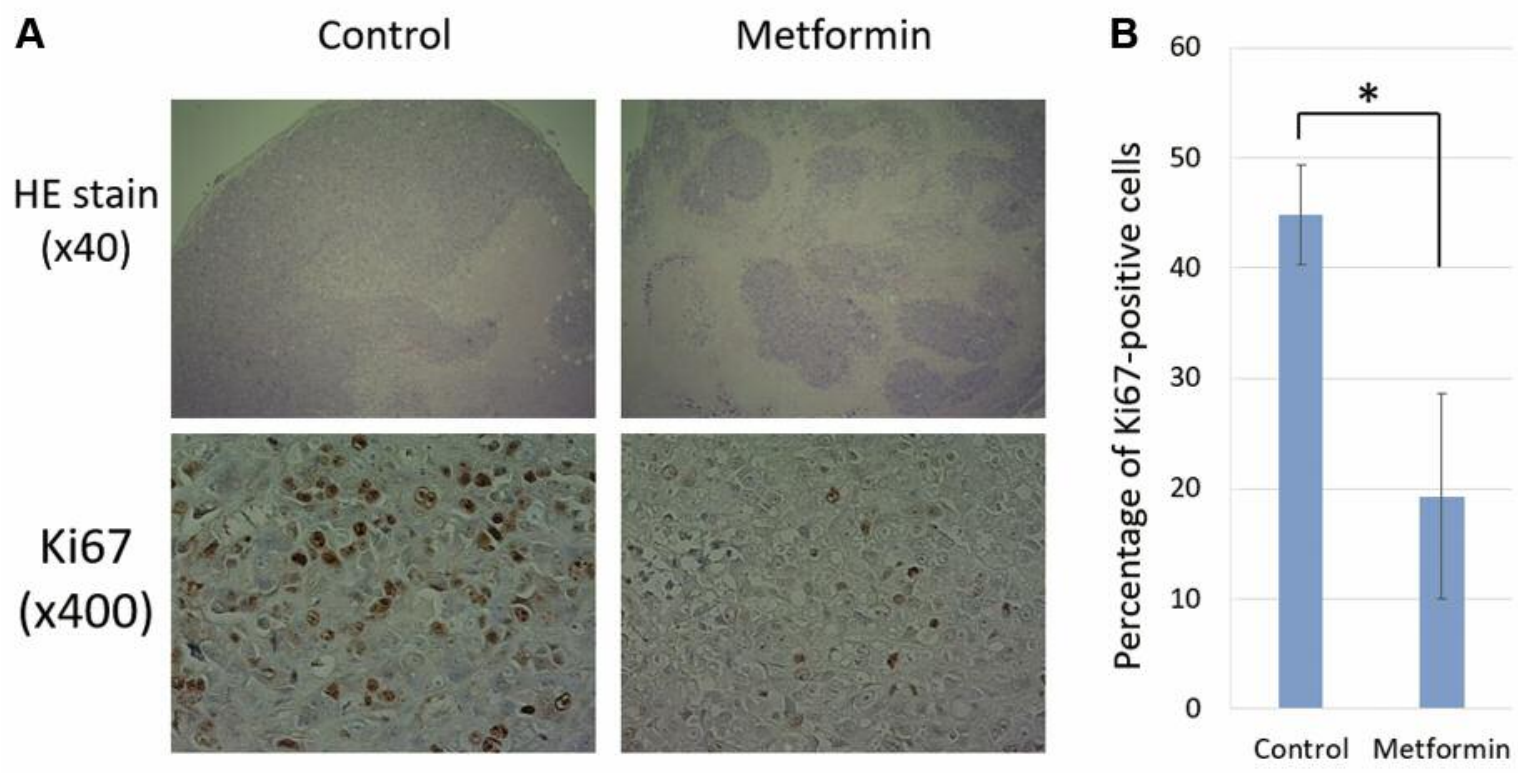

Figure 3. Tumor histology in a mouse xenograft model of gastric cancer (MKN45-GFP). A: The histology of the tumors is shown. Hematoxylin and eosin (HE) staining and Ki67 staining were performed on the tumors in the control group and the metformin-treated group. B: The percentage of Ki67-positive cells, representing cell proliferation, in the tumors is shown. Control group: $n=4$, metformin-treated group: $n=4$. *Significantly different at $p=0.011$. Data are means \pm S.D.

the AMPK pathway (LKB1, p-AMPK $\alpha$ and AMPK $\alpha$ ) were detected by western blotting (Figure 4A) and quantified using Image $\mathrm{J}$. The relative expression was calculated using the GAPDH expression for normalization. There were no significant differences between the control group and metformin-treated group in the expression of LKB1 $(p=0.311), \mathrm{p}-\mathrm{AMPK} \alpha(p=0.885)$ or AMPK $\alpha(p=0.108)$ (Figure $4 \mathrm{~B}$, respectively). 


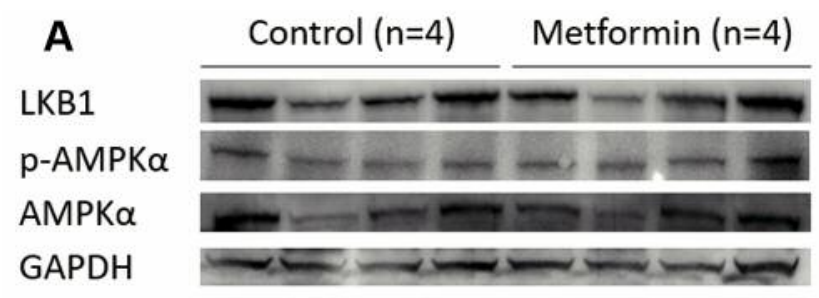

B

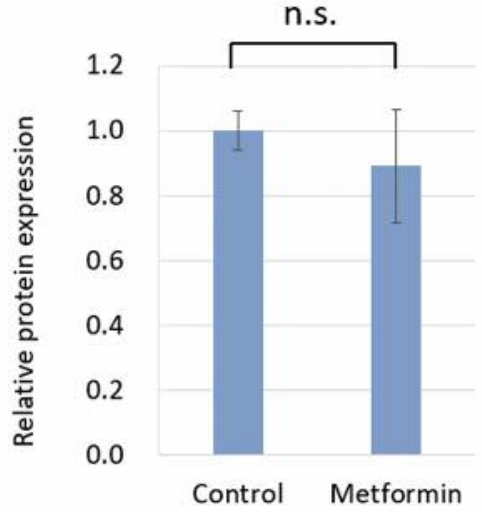

$\mathrm{p}-\mathrm{AMPK} \alpha$

n.s.

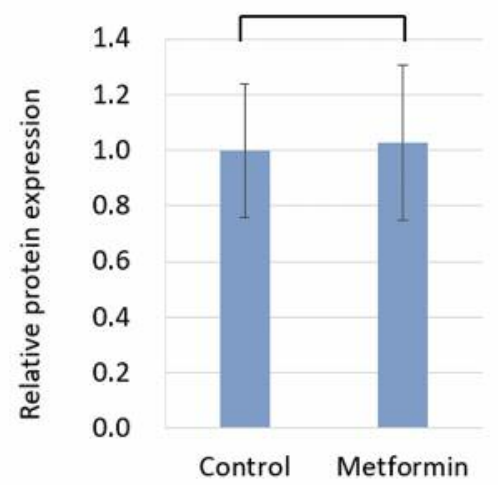

AMPK $\alpha$

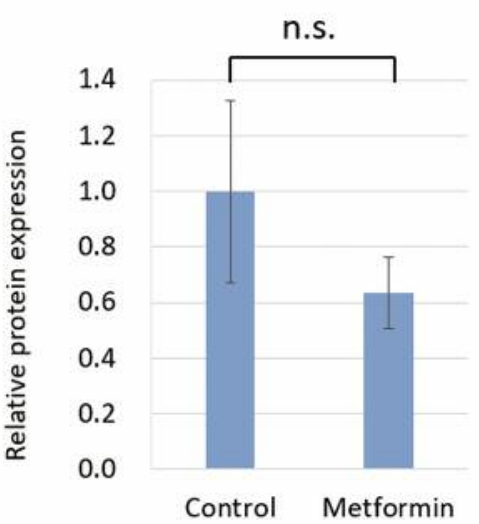

Figure 4. The effect of metformin on the 5' adenosine monophosphate-activated protein kinase (AMPK) pathway in vivo evaluated by a western blot analysis. The results of the evaluation of protein expression levels in peritoneal tumors in xenograft modes determined by a western blot analysis (control group; $n=4$ and metformin group; $n=4)(A)$. The protein expression was evaluated using Image $J$, and the relative expression was calculated using glyceraldehyde 3-phosphate dehydrogenase (GAPDH) expression for normalization (B). There were no significant differences in the protein

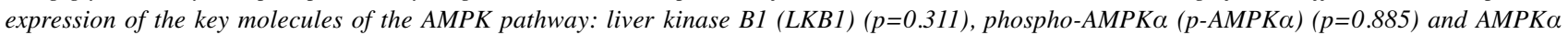
$(p=0.108)$. Data are means \pm S.D. n.s.: Non-significant.

$N F-\kappa B$ activity. The effect of metformin on the NF-kB expression was determined by a western blotting analysis (Figure 5A). The relative protein expression of NF- $\mathrm{kB}$ was calculated in the same way as the AMPK pathway proteins. The relative protein expression of NF-kB was significantly lower in the metformin-treated group than in the control group (Figure 5B, $p=0.032$ ).

\section{Discussion}

It has been reported that metformin suppresses GC in vitro and in vitro. Our study further clarified that the sensitivity to metformin was increased at low glucose concentrations in vitro. Furthermore, metformin suppressed peritoneal metastasis of GC cells in vivo.

A detailed analysis of the formed tumors confirmed that cell proliferation was enhanced in the tumors. Cell signals were also examined, and the results indicated that the AMPK pathway was not substantially altered and that NF-kB signaling was suppressed by metformin administration. These results suggest that metformin inhibits peritoneal metastasis of GC and that the NF- $\mathrm{kB}$ signal inhibitory action of metformin is important as part of its mechanism.

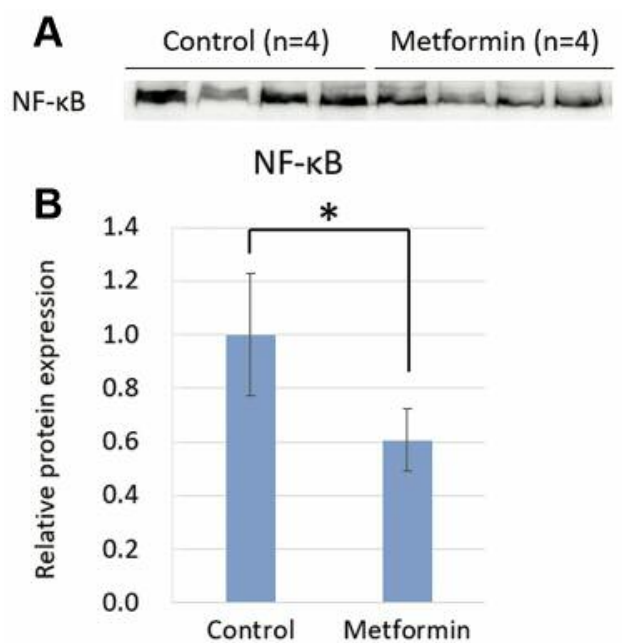

Figure 5. The effect of metformin on nuclear factor-kappa $B(N F-k B)$ in vivo, as evaluated by a western blot analysis. Protein expression levels of $N F-k B$ were evaluated in peritoneal tumors in xenograft models as determined by a western blot analysis (control group; $n=4$ and metformin group; $n=4)(A)$. The protein expression was evaluated using Image $J$ and the relative expression was calculated using glyceraldehyde 3-phosphate dehydrogenase $(G A P D H)$ expression for normalization $(B) . N F-k B$ protein expression was significantly reduced by metformin administration. *Significantly different at $p=0.032$. Data are means \pm S.D. 
On examining the growth-suppressive effect of metformin in vitro, metformin showed a dose-dependent growthinhibitory effect in all GC cell lines. Since it has been reported that the concentration of glucose in solid tumor is $\leq 0.5 \mathrm{mM}$ (14) and that the glucose concentration of culture medium affects metformin sensitivity (13), we examined the influence of the glucose concentration in the medium on the activity of metformin. When the glucose concentration in the medium was $0.5 \mathrm{mM}$, the $\mathrm{IC}_{50}$ concentration was greatly reduced in several GC cell lines (MKN1, KATO-III and SNU-1). This result showed that the sensitivity to metformin was indeed affected by the glucose condition.

The metformin concentration needed to exert tumorsuppressing action is reported to differ markedly between in-vitro experimental systems and in vivo models. The amount of metformin administered in this xenograft model $(5 \mathrm{mg} / \mathrm{mice}, 250 \mathrm{mg} / \mathrm{kg}$ ) produces a plasma concentration of 5- $\mu \mathrm{M}$ metformin (24), suggesting that findings obtained in vitro may not be reflected in vivo. The results of the present study suggest that the intracellular signals influenced by glucose may affect sensitivity to metformin. When studying the antitumor effect of metformin in solid tumor cells in vitro, it may be more meaningful to perform experiments under low-glucose conditions reflecting the tumor environment. In addition, the cytotoxic effects of metformin, such as suppression of cell proliferation, may act specifically in solid tumors under low-glucose conditions, as these actions are not demonstrated under high-glucose conditions.

In the present study, the tumor volume of peritoneal metastasis was significantly reduced by metformin administration. Although body weight loss was observed during the course of treatment, no clear difference was shown between the control group and the metformin-treated group. The body weight loss observed is considered to be an effect of peritoneal metastasis. We further analyzed the tumor to elucidate the mechanism underlying metformin and found that proliferation was suppressed in the tumor. This examination is believed to reflect the actual clinic setting, as it was performed using a mouse model in which metformin had been administered at a therapeutic dose in vivo. Regarding cell signaling, no obvious changes in the AMPK pathway, which is the main target signal of metformin, were noted, although the NF-kB signal, another important signal, was significantly suppressed. NF-KB also plays an important role in the development of peritoneal metastasis (15), and this signal was considered to be more important than AMPK in the inhibitory action exerted by metformin on peritoneal metastasis in this study.

Metformin exerts an inhibitory effect on GC and peritoneal metastasis and may also suppress NF- $\mathrm{kB}$ signalling. These results suggest that metformin may be a useful drug for the treatment of GC with peritoneal metastasis.

\section{Statement of Ethics}

Animal experiments conformed to internationally accepted standards and were approved by the appropriate institutional review body (approval number 28-208).

\section{Conflicts of Interest}

The Authors declare that they have no competing interests in regard to this study.

\section{References}

1 Kono K, Yong WP, Okayama H, Shabbir A, Momma T, Ohki S, Takenoshita $\mathrm{S}$ and So J: Intraperitoneal chemotherapy for gastric cancer with peritoneal disease: experience from Singapore and Japan. Gastric Cancer 20(Suppl 1): 122-127, 2017.

2 Noto H, Goto A, Tsujimoto T and Noda M: Cancer risk in diabetic patients treated with metformin: a systematic review and meta-analysis. PLoS One 7(3): e33411, 2012.

3 Fujita K, Iwama H, Miyoshi H, Tani J, Oura K, Tadokoro T, Sakamoto T, Nomura T, Morishita A, Yoneyama H and Masaki $\mathrm{T}$ : Diabetes mellitus and metformin in hepatocellular carcinoma. World J Gastroenterol 22(27): 6100-6113, 2016.

4 Fujimori T, Kato K, Fujihara S, Iwama H, Yamashita T, Kobayashi K, Kamada H, Morishita A, Kobara H, Mori H, Okano K, Suzuki Y and Masaki T: Antitumor effect of metformin on cholangiocarcinoma: In vitro and in vivo studies. Oncol Rep 34(6): 2987-2996, 2015.

5 Abdelsatir AA, Husain NE, Hassan AT, Elmadhoun WM, Almobarak AO and Ahmed MH: Potential benefit of metformin as treatment for colon cancer: the evidence so far. Asian Pacific J Cancer Prev 16(18): 8053-8058, 2015.

6 Zhou PT, Li B, Liu FR, Zhang MC, Wang Q, Li YY, Xu C, Liu $\mathrm{YH}$, Yao Y and Li D: Metformin is associated with survival benefit in pancreatic cancer patients with diabetes: a systematic review and meta-analysis. Oncotarget 8(15): 25242-25250, 2017.

7 Grossmann ME, Yang DQ, Guo Z, Potter DA and Cleary MP: Metformin Treatment for the Prevention and/or Treatment of Breast/Mammary Tumorigenesis. Curr Pharmacol Rep 1(5): 312323, 2015.

8 Dilokthornsakul P, Chaiyakunapruk N, Termrungruanglert W, Pratoomsoot C, Saokaew S and Sruamsiri R: The effects of metformin on ovarian cancer: a systematic review. Int J Gynecol Cancer 23(9): 1544-1551, 2013.

9 Cai X, Hu X, Tan X, Cheng W, Wang Q, Chen X, Guan Y, Chen $C$ and Jing $X$ : Metformin induced AMPK activation, $G_{0} / G_{1}$ phase cell-cycle arrest and the inhibition of growth of esophageal squamous cell carcinomas in vitro and in vivo. PLoS One 10(7): e0133349, 2015.

10 Micic D, Cvijovic G, Trajkovic V, Duntas LH and Polovina S: Metformin: Its emerging role in oncology. Hormones 10(1): 515, 2011.

11 Lei Y, Yi Y, Liu Y, Liu X, Keller ET, Qian CN, Zhang J and Lu $\mathrm{Y}$ : Metformin targets multiple signaling pathways in cancer. Chin J Cancer 36(1): 17, 2017.

12 Sekino N, Kano M, Matsumoto Y, Sakata H, Akutsu Y, Hanari N, Murakami K, Toyozumi T, Takahashi M, Otsuka R, Yokoyama M, Shiraishi T, Okada K, Hoshino I, Iida K, Akimoto 
AK and Matsubara $\mathrm{H}$ : Antitumor effects of metformin are a result of inhibiting nuclear factor kappa $\mathrm{B}$ nuclear translocation in esophageal squamous cell carcinoma. Cancer Sci 109(4): 1066-1074, 2018.

$13 \mathrm{Yu} \mathrm{H}, \mathrm{Bian} \mathrm{X}, \mathrm{Gu} \mathrm{D}$ and He X: Metformin synergistically enhances cisplatin-induced cytotoxicity in esophageal squamous cancer cells under glucose-deprivation conditions. BioMed Res Int 2016:8678634I, doi: 10.1155/2016/8678634.2016.

14 Schroeder T, Yuan H, Viglianti BL, Peltz C, Asopa S, Vujaskovic $\mathrm{Z}$ and Dewhirst MW: Spatial heterogeneity and oxygen dependence of glucose consumption in R3230Ac and fibrosarcomas of the Fischer 344 rat. Cancer Res 65(12): 5163 $5171,2005$.

15 Zhou XL, Xue WH, Ding XF, Li LF, Dou MM, Zhang WJ, Lv Z, Fan ZR, Zhao J and Wang LX: Association between metformin and the risk of gastric cancer in patients with type 2 diabetes mellitus: a meta-analysis of cohort studies Oncotarget 8(33): 55622-55631, 2017.

16 Spillane S, Bennett K, Sharp L and Barron TI: Metformin exposure and disseminated disease in patients with colorectal cancer. Cancer Epidemiol 38(1): 79-84, 2014.

17 Kanda M and Kodera Y: Molecular mechanisms of peritoneal dissemination in gastric cancer. World J Gastroenterol 22(30): 6829-6840, 2016.

18 Valaee S, Yaghoobi MM and Shamsara M: Metformin inhibits gastric cancer cells metastatic traits through suppression of epithelial-mesenchymal transition in a glucose-independent manner. PLoS One 12(3): e0174486, 2017.

19 Chen G, Feng W, Zhang S, Bian K, Yang Y, Fang C, Chen M, Yang $\mathrm{J}$ and Zou X: Metformin inhibits gastric cancer via the inhibition of HIF1alpha/PKM2 signaling. Am J Cancer Res 5(4): 1423-1434, 2015.
20 Lamouille S, Xu J and Derynck R: Molecular mechanisms of epithelial-mesenchymal transition. Nat Rev Mol Cell Biol 15(3): 178-196, 2014

21 Wu SM, Lin WY, Shen CC, Pan HC, Keh-Bin W, Chen YC, Jan YJ, Lai DW, Tang SC, Tien HR, Chiu CS, Tsai TC, Lai YL and Sheu ML: Melatonin set out to ER stress signaling thwarts epithelial mesenchymal transition and peritoneal dissemination via calpain-mediated C/EBPbeta and NFkappaB cleavage. J Pineal Res 60(2): 142-154, 2016.

22 Courtois S, Duran RV, Giraud J, Sifre E, Izotte J, Megraud F, Lehours P, Varon C and Bessede E: Metformin targets gastric cancer stem cells. Eur J Cancer 84: 193-201, 2017.

23 Yamamoto M, Taguchi Y, Ito-Kureha T, Semba K, Yamaguchi N and Inoue J: NF-kappaB non-cell-autonomously regulates cancer stem cell populations in the basal-like breast cancer subtype. Nat Commun 4: 2299, 2013.

24 Takase O, Yoshikawa M, Idei M, Hirahashi J, Fujita T, Takato $\mathrm{T}$, Isagawa T, Nagae $\mathrm{G}$, Suemori $\mathrm{H}$, Aburatani $\mathrm{H}$ and Hishikawa $\mathrm{K}$ : The role of NF-kappaB signaling in the maintenance of pluripotency of human induced pluripotent stem cells. PLoS One 8(2): e56399, 2013.

25 Chandel NS, Avizonis D, Reczek CR, Weinberg SE, Menz S, Neuhaus R, Christian S, Haegebarth A, Algire C and Pollak M: Are metformin doses used in murine cancer models clinically relevant? Cell Metab 23(4): 569-570, 2016.

Received September 14, 2018

Revised September 29, 2018 Accepted October 8, 2018 